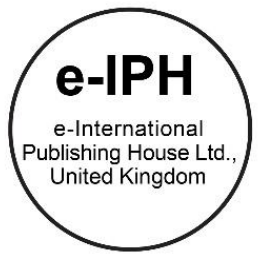

\title{
Barriers of Adopting Environmental Management Practices in the Micro and Small Island Chalets Operation
}

\author{
Mariam Jamaludin ${ }^{1 *}$, Zeenat Begam Yusof 2 \\ ${ }^{1}$ Faculty of Architecture, Planning and Surveying, Universiti Teknologi MARA, 40000 Shah Alam, Malaysia \\ ${ }^{2}$ Kulliyyah of Architecture and Environmental Design, International Islamic University Malaysia, 50728 Kuala Lumpur, Malaysia
}

\begin{abstract}
Sustainability becomes main management issues for hospitality firms. Big hospitality firms conduct countless attempts to accommodate into the sustainability agenda. However, the small hospitality firms are left behind. The reason is some barriers that are dragging them. Barriers studies regarding big hospitality companies are plenteous. However, studies regarding barriers of MSIC operators are limited in Malaysia. Therefore, the objectives are to identify the barriers and the ranking of the barriers. This study is applying the quantitative and qualitative approach. The finding shows that lack of green products is the most salient barrier. In conclusion, this study has managed to identify barriers and provide some recommendations.

(C) 2016. The Authors. Published for AMER ABRA by e-International Publishing House, Ltd., UK. Peer-review under responsibility of AMER (Association of Malaysian Environment-Behaviour Researchers), ABRA (Association of Behavioural Researchers on Asians) and cE-Bs (Centre for Environment-Behaviour Studies, Faculty of Architecture, Planning \& Surveying, Universiti Teknologi MARA, Malaysia.
\end{abstract}

Keywords: Barriers; green practices; relative importance index; micro and small island chalet

\section{Introduction}

Environmental management practices are buzzwords for all industries in the world. Industries are pushed to adopt green practices in their operation due to degradation of the natural environment and various driving factors. The driving factors are such as consumer demands, financial benefits, political agenda, competitiveness and legitimation (Yusof \& Jamaludin, 2013). Among all the industries, the hospitality industry is also equally involved in this matter. Even though, this industry is not a major contributor to the deterioration of the environment compared to other industries (David \& Kirk, 1995). But, still it provides significant ecological footprints through the excessive use of the energy, water, and natural resources (Chan, 2011). According to Bohdanowicz (2005) a typical hotel in the UK annually releases between $160 \mathrm{~kg}$ to $200 \mathrm{~kg}$ of carbon dioxide per square meter of a room and produce about $1 \mathrm{~kg}$ of waste per guest per day. If the amount of the carbon released in a single day counted cumulatively, the figures would be worrisome. Therefore, adhering to these externalities the industry has taken many proactive roles in the environmental conservation and preservation. The hospitality industry has produced formal environmental

\footnotetext{
${ }^{*}$ Corresponding author. Tel.: +0-000-000-0000 ; fax: +0-000-000-0000 .

E-mail address: marja67@gmail.com
} 
instruments such as best environmental practices, eco-labels, Environmental Management System (EMS), environmental performance indicators and green certifications (Ayuso, 2006). Most of the chain-affiliated hotels have started to incorporate environmental instruments in their management and operation. Presently, hoteliers are more active in applying ISO Standard and green certification to keep up the good brand image (Bohdanowicz, 2006).

However, the condition is reversed for the Small-Medium Enterprise (SME) operators. They have small capabilities of financial resources. Small capital hindered them to involved in the corporate environmentalism (Tzschentke, Kirk, \& Lynch, 2008). The financial limitation is one of the barriers identified. However, there are many more barriers. Studies regarding the barriers are very limited especially for SME hospitality firms in Malaysia. Therefore, this study is conducted to fulfill the gap in the literature. The objectives of this study are to determine the barriers faced by the Micro and Small Island Chalets (MSIC) operators and to determine the level of the barriers.

SMEs in Malaysia are divided into three categories: (1) Micro, (2) Small and (3) Medium. This study is focusing on the Micro and Small Enterprises (MSEs) due to the high number of these enterprises on the Marine Park Islands in Malaysia. According to Gopal \& Mohd Sulaiman (2013), these enterprises are identified through the sales turnover or numbers of full-time employees. Sales turnover is less than RM300, 000 or employee less than five staffs considered as Micro Enterprise. Whereas, sales turnover from RM 300,000 to less than RM 3 million considered as the Small Enterprise.

\section{Literature Review}

The concept of sustainability emerged in 1987 when Gro Harlem Brundtland produces a report "Our Common Future" for United Nation, which defines the meaning of sustainable development. The meaning of sustainable development is "development that meets the needs of the present without compromising the ability of future generations to meet their needs" (Butler, 2007). Since then, sustainable development becomes an important matter for government and private organization in the world. Various industries including the tourism industry started to incorporate the concept of sustainability in their operation.

The tourism industry is incorporating the sustainability measures due to its negative externalities. This industry produces the excessive amount of solid waste, carbon dioxide and the use excessive amount of energy and water. Apart from environment deterioration, there are other factors that are forcing tourism industry to incorporate sustainable measures. The factors are growing pressure from the environmental groups, regulatory compliance, financial benefits, green consumers pressure, image branding and competitiveness (Eric S.W Chan \& Wong, 2006; Molina-Azorín et al., 2009; Rahman, Reynolds, \& Svaren, 2012; Tzschentke et al., 2008; Yusof \& Jamaludin, 2013). Beside these common factors, other driving factors are manager positive attitude towards green strategies (Bohdanowicz, 2005), location of the hotel in the sensitive area (Jamaludin \& Yusof, 2013), firm resources capabilities, enhancement of employees job satisfaction and moral reasons (Rahman et al., 2012).

Many attempts are taken by big hospitality firms to become green operators. Hoteliers formalized their green practice by adopting Environmental Management system (EMS) to comply the ISO 14001 Standard. According to Chan \& Wong (2006) the ISO 14001 Standard helps hospitality firms to implement the EMS. EMS consists of five core principles such as (1) environmental policy, (2) planning, (3) implementation and operation, (4) checking and corrective action and (5) management review. Besides, the ISO Standard, some hospitality firms are applying green certifications. Currently, there are more than 800 green certifications worldwide. Some examples of the prominent green certification are LEEDs, BREEAM, EarthCheck, Green Star and Green Mark. Each country has owned green certifications for hospitality firms to apply.

Some research suggested that adopting green strategies in the management could represent the substantial opportunity for the firms (Kamalul Ariffin, Khalid, \& Wahid, 2013). However, not doing so can cause damaging effects (Bansal \& Roth, 2000; Menon, Menon, Chowdhury, \& Jankovich, 1999). Where else, other research acknowledged that the adoption of green strategies in the management needs cautiousness because sometimes the cost of green products or system may outweigh the businessassociated benefits (Chen \& Chang, 2012). Hospitality firms need to face several barriers before adopting green strategies in their management. Several pieces of literature are identified and discussed in the subsequent section.

\subsection{Studies of barriers in hospitality industry}

Studies regarding barriers to environmental management practices for industries are a plethora. Some of the examples are: barriers to sustainable facility management in Nigeria by (Ikediashi, Ogunlana, Oladokun, \& Adewuyi, 2013), barriers of organization in implementing green marketing strategies by (Ramirez, 2010), barriers to implementing EMS in organization by (Kirkland \& Thompson, 1999) and barriers to adopting EMS by all type of SMEs (McKeiver, 2005). 
However, environmental management practices for the hospitality industry is limited. Only several studies have conducted in this area. For example, the first study was conducted by (Eric S.W. Chan, 2008). The study aim was to determine the barriers to EMS in the hotel industry in Hong Kong. This study has identified six barriers. The example of barriers are (1) lack of knowledge and skills, (2) lack of professional advice, (3) uncertainty of outcome, (4) lack of certifiers/verifiers, (5) lack of resources and (6) implementation and maintenance cost.

The second study conducted by Yusof \& Jamaludin (2014). The aim of the study was to identify significant, non-significant and less significant barriers faced by the Malaysia green hotels and resort operators. This study has identified 12 barriers from the literature. The summary of the barriers shown in Table 1.

Table 1. Barriers to the study identified

\begin{tabular}{ll}
\hline Barriers & Level of significant \\
\hline High implementation cost & Less significant \\
Lack of green information and knowledge & Nonsignificant \\
Lack of green experts & Significant \\
Uncertainty of green outcome & Nonsignificant \\
Lack of resources such as manpower and equipment & Significant \\
Lack of support from owner and management & Nonsignificant \\
Lack of government regulation and enforcement & Less significant \\
High maintenance cost & Nonsignificant \\
$\begin{array}{l}\text { Difficulty in balancing the quality of service } \\
\text { performance }\end{array}$ & with environmental \\
Lack of consumer supports & Significant \\
Lack of networking with green suppliers & \\
Difficulty in managing and training staffs & Nonsignificant \\
\hline
\end{tabular}

The third study conducted by (Graci, 2006). This study examines barriers faced by hospitality operators in Gili Trawangan, Indonesia in implementing sustainable tourism initiatives. The study identifies four barriers: (1) inadequate resources, (2) lack of momentum from the business owner, (3) island culture, (4) government corruption and (4) lack of infrastructure.

\subsection{Barriers of MSEs in adopting environmental management practices}

SME is the largest business sectors, which generate up to $60 \%$ of the global economic input. Among the five SME sectors in Malaysia, service sector has the highest distributions of SMEs $(90 \%)$ compared to manufacturing $(5.9 \%)$, agriculture $(1 \%)$, construction (3\%) and mining (0.1\%) (Corporation, 2011). Even though percentage shows that the numbers of SMEs in hospitality sector in Malaysia are quite high. Studies regarding barriers of environmental management practices for SME hospitality industry are very limited. Therefore, this study is conducted to fulfill the literature gap.

Generally, Medium and Small Enterprises known as more 'pollution-intensive' business compared to big business due to the cumulative negative impacts of their operation on the natural environment (Kasim, 2009; Yacob, Aziz, Mohamad Makmor, \& Mohd Zin, 2013). Most of the MSEs in Malaysia located in the tourism area, which are highly environmental sensitive areas such as islands, beaches, forest, and mangrove. There are growing bodies of literature that support the MSEs should engage in environmental management practices due their cumulative negative externalities (Chan, 2011; Kasim, 2009).

However, most of the studies agreed that MSEs are less likely to have environmental management plans due to the several barriers (Kasim, 2009; Thomas, Shaw, \& Page, 2011; Walker, Janice, Lynnaire, Calvin, \& Ute, 2008; Yacob et al., 2013). Studies have identified SMEs barriers are from two perspectives (Walker et al., 2008; Yacob \& Moorthy, 2012).

The first perspective is from the owner/manager side. As for the owner/manager side, there are three areas of barriers: (1) characteristics of the MSEs in general, (2) resource availability (financial, human and time) and (3) owner/manager knowledge, interest and motivation.The characteristics of the MSEs, in general, are the first type of barriers, which are pulling them back from being green operators. 
According to Hillary (2004) MSEs general characteristic is heterogeneous. The heterogeneous characteristics of MSEs are unique location, operate by independent owner (man or women) of all ages and have different education level (McKeiver, 2005). The heterogeneous nature makes it difficult for the government to communicate with the operators in terms of technical and environmental training. They usually operate their business based on their experiences.

The limitations of resources are the second type of barrier. This barrier is related to the limitation of (1) financial capacity, (2) limitation of human resources and (3) time (Hillary, 2004). Commonly, small financial capacity hindered the MSE operators to invest in the environmental management plan (Jaafar, Ing, \& Mohd Sukarno, 2011). Often, operators in lodging industry feel that investment in environmental management is an additional business investment. The profits gain from the business usually just enough for buying equipment and paying the staffs. Sometimes, owner/manager are not sure that the implementation of green strategies will have a return on their investment (Kasim, 2009).

In terms of human resource, MSE operators usually employ less than five staffs, which unlikely have dedicated environmental staffs. Sometimes, the staffs are the family members or local people staying nearby. Islanders on the Malaysian Islands have low education level due to the limitation of education facilities in the Islands. Therefore, to have staffs that are expert in the environmental practices is impossible.

The last limitation is time. Tremendous arrivals of tourist at the Islands causing the operators busy in managing guests compared to engaging in the environmental practices. Moreover, to implement green practices in the operation it required longer time frame for the system to function.

The third type of barrier is knowledge, interest and motivations of the owner/manager. Many of the MSE operators have the lack of knowledge regarding the sustainability practices, the benefits of the environmental improvements, environmental issues and risks posed by their operation due to the low education level and ignorance of the operators (Kasim, 2009). The ignorance of the operators is strongly related to the feeling of unmotivated. The operators feel unmotivated because they have to use their personal capital to invest in environmental practices, which usually did not give an immediate return (Graci, 2006). So they usually pose a question 'what's in it for me'. For them, environmental practices are the burden (Walker et al., 2008).

The second perspective for barriers is from the government or agency side. Barriers identified are (1) lack of communication (2) lack of stakeholder engagement and (3) lack of legislation. Lack of communication between government and MSE operators hampered environmental commitment. Most of the time, environmental strategies, best practice, green guidelines only found in papers, seldom reach to the operators. Other than that, lack of information regarding environmental practices benefits, inadequate information regarding environmental programs and the use of very technical or academic language by the government agencies also hindered the MSE operators to adopt green practices (Walker et al., 2008). The second barrier is less engagement from the stakeholder. The MSE operators always find that there are little pressure and support from the stakeholder such as the environmental organization, government, landlord, and guests to implement environmental strategies (Kasim, 2009). The third barrier is the lack of legislation. The environment legislation exists in most of the countries. However, the enforcement is missing. The enforcement in Malaysia is missing at the State level due to the (1) lack of staffs, (2) lack financial capability, (3) lack of support from the federal government and (4) lack of collaboration between departments and agencies. On the other side, environmental management system, standards, and certifications are only designed for big business not for the small business. Therefore, the MSEs, found these standards and certifications are costly to implement and to maintain (Walker et al., 2008).

\section{Methodology}

This study employed qualitative and quantitative approach. The quantitative data are analyzed using descriptive analysis test. The questionnaire was administered by hand to all MSE owner/manager at the Four Marine Park Islands in Malaysia. The islands were Perhentian Island, Kapas Island, Redang Island and Tioman Island. Tioman Island located in Pahang. Whereas, the other three Islands located in Terengganu. As for qualitative approach MSE, operators are randomly selected for interviews. Four operators interviewed for each island. Open-ended interview questionnaire was prepared.

\subsection{Sample and method of data collection}

The main method of the study is quantitative analysis. The barriers or factors of the questionnaire were prepared through content analysis of few studies, which discussed above such as (Graci, 2006, Chan, 2011,Yusof \& Jamaludin, 2014). The content validity of the questionnaire pretested among the selected academician in International Islamic University Malaysia 
(IIUM) from Kulliyyah of Architecture and Environmental Design (KAED). The questionnaire was consists of two parts. Part1: background of the MSEs and Part 2: the factors. 11 factors identified. The factors are:

- Lack of information and knowledge on the green practices

- High implementation and maintenance cost

- Lack of financial capabilities- small size

- Lack of government support

- Lack of government enforcement regarding green practices implementation

- Isolation and transportation problem

- Lack of resources such as freshwater and electricity

- Lack of human resources especially trained staffs in the green practices management

- Lack of support from the owner

- Less support from the tourists on green initiatives

- Lack of green products and suppliers contact in the market

The factors are tested using five points Likert Scale ranging from 1= Strongly Disagree to $5=$ Strongly Agree. Questionnaires were distributed to 100 operators on the four Marine Park Islands and 85 operators did response. The response rate was $85 \%$, which is quite high. The respondents were owner/manager of the chalets. The reliability test was conducted to ensure that the measure of the factors had internal consistency across time and across the various factors measured (Sekaran, 2009). The reliability test conducted by referring to Cronbach's Alpha score. The (a) score was 0.735 . The score shows that the all the factors exceed the minimum value of 0.70 (Hair et.al, 2010). Thus, can be concluded that the factors have the acceptable level of reliability. Significance test also conducted. The probability scores achieved for each variable is $p<0.001$ using Pearson ChiSquare test. Thus, can be concluded that the pattern of the variable score is significant.

\subsection{Profile of respondents}

The respondents from Tioman Island were 40 operators (46.5\%), Kapas Island were 8 operators (9.3\%), Perhentian Island was 29 operators (23.8\%) and Redang Island was 8 operators (10.5\%). $80 \%$ of the respondents are male, and $20 \%$ are female. $4.7 \%$ of the respondents have primary education level, $70.6 \%$ of the respondents have secondary education level and $24.7 \%$ respondents have the high education level (diploma, certification, and degree). Therefore, the study shows that most of the owner/managers does not have a high education level. $55.3 \%$ of the operators received less than RM 300,000 yearly net income, $32.9 \%$ received between RM 300,000 to RM 1 million and $11.8 \%$ of the operators received more than RM 1 million up to RM 3 million. The finding indicates that most of the operators on the islands are fall under the category of Microenterprises.

\section{Findings and Discussion}

The descriptive statistics presented in Table 2 indicated that the lack of green product and supplier contact in the market has the highest mean score (4.58), followed by the isolation and transportation problem (4.55). Subsequent factor is high implementation and maintenance cost (4.53), lack of trained staffs in green practices management (4.52), lack of information and knowledge on the green practices (4.44) and so on (Refer to Table 1).

This study indicates that $74.1 \%$ of the MSE operators strongly agreed that lack of green product and supplier contact in the market were the most significant barrier that are hindering them from implementing environmental practices. The reason is green practices recently introduced in Malaysia, and green products and suppliers limited in Malaysia. Green products can only found in big cities compared to small islands.

The second highest barrier identified was isolation and transportation problem. About $72.9 \%$ operators strongly agreed that this factor is a barrier. These islands located far from the mainland. It takes about 1-2 hours to reach these islands by ferry or boat. Therefore, it is difficult for the operators to purchase unnecessary goods or equipment due to the high transportation cost. Furthermore, isolation also hindered green knowledge to reach them due to unavailability of the telecommunication system and Internet access.

Attention grabbing finding from this study is high implementation and maintenance cost is the third barrier, not the first barriers as claimed by many previous studies because few operators on the islands do not agree that implementation and 
maintenance cost is a barrier. According to them, green practices can be achieved without implementing expensive green strategies but through environmental behavior. Environmental behavior such as minimizing the use of energy, water, and goods can save energy, water and reduce the amount of waste produced.

The fourth highest barrier identified is the lack of trained staffs in green practice management. Micro operators usually have less than five staffs, and sometimes the family members are the staffs. Therefore, to have dedicated environmental officer are not possible. Most of the MSE operators have the small capital to trained or send their staffs for environmental training and programs. The moderate barriers are the lack of green knowledge, small financial capacity, lack of government support and enforcement. These barriers mentioned in section 2.2 .

The second last low barrier identified is the lack of support from the owner (V11). This factor considered as low barriers because most of the owner/manager is very supportive of the idea of implementing environmental practices, but they are not fully ready to implement in their operation. The last factor, which considered not as the barrier is the lack of support from tourists (V12). 50\% of the operators disagreed that there is the lack of support from the tourist. According to them, most of the international tourists are very supportive regarding environmental practices. They often involved in beach cleaning program organized by the operators. Some of them give the big hand to the local people and operators to protect the surrounding environment.

\section{Conclusion}

In conclusion, this study has identified the barriers that are hindering the MSE operators in Malaysia from implementing environmental management practices. This study also has shown different outcome from the previous study. The different outcome is the lack of green product and suppliers are the most significant barriers compared to the Chan (2011) study, which is high implementation and maintenance cost. Therefore, can be concluded that operators in Malaysia are pulled back from applying green products or system in their operation due to the lack of the product itself. Hence, the government needs to take the lead in bringing or introducing more green products and suppliers in the Malaysian market. The authorities need to provide shops near the jetty area, which help the green suppliers, to sell their green products to the operators. Basic products such as green toiletries, greenwashing detergents, biodegradable plastic bags, recycled products and many more.

Besides providing the facilities, the government needs to educate the operators. Education regarding environmental practices is very crucial for the operators because of their cumulative negative impacts on the marine environment. They should inform regarding the barriers, the negative impacts of their operation, the benefits of being green, funding that they can apply and green products and system available in the market. Support from the government and other stakeholders are very important for the operators to become green operators. Where else, the operators also should be more open-minded in implementing the environmental practices in their operation.

The study is conducted for the Micro and Small Enterprises only. The findings cannot generalize to Medium Enterprises and other sector under the SMEs. This study cannot consider as the comprehensive study because many other islands not covered in this study due to the time and cost barriers.

\section{Acknowledgement}

This study was funded by IIUM study grant. This study is a part of corresponding author's PhD. study at the Universiti Teknologi MARA (UITM), Shah Alam Malaysia.

\section{References}

Ayuso, S. (2006). Adoption of Voluntary Environmental Tools for Sustainable Tourism: Analysing the Experience of Spanish Hotel. Corporate Social Responsibility and Environmental Management, 13(4), 207-220.

Bansal, P., \& Roth, K. (2000). Why companies go green: a model of ecological responsiveness. Academy of Management Journal, 43(4), 717-736.

Bohdanowicz, P. (2005). European hoteliers environmental attitudes greening the business. Cornell Hotel and Restaurant Administration Quarterly, 46, 188-204. doi:10.1177/0010880404273891

Bohdanowicz, P. (2006). Environmental awareness and initiatives in the Swedish and Polish hotel industries-survey results. International Journal of Hospitality Management, 25(4), 662-682. 
Jamaludin, M., \& Yusof , Z.B., / 6 th AicE-Bs2015Barcelona, Spain, 30 Aug.- 04 Sep. 2015 / E-BPJ, Maiden Issue, 1(1) June 2016 (pp.171-177)

Bohdanowicz, P., Zientara, P., \& Novotna, E. (2011). International hotel chains and environmental protection : an analysis of Hilton 's we care prgramme. Journal of Sustainable Tourism, 19(7), 797-816.

doi:10.1080/09669582.2010.549566

Butler, R. W. (2007). Sustainable tourism: A state-of-the-art review. Tourism Geographies, 1(1), 7-25. doi:10.1080/14616689908721291

Chan, E. S. ., \& Wong, S. C. . (2006). Motivations for ISO 14001 in the hotel industry. Tourism Management, 27, 481-492. doi:10.1016/j.tourman.2004.10.007

Chan, E. S. W. (2008). Barriers to EMS in the hotel industry. International Journal of Hospitality Management, 27(2), 187-196. doi:10.1016/j.jihm.2007.07.011

Chan, E. S. W. (2011). Implementing Environmental management systems in Small and Medium sized hotels: Obstacles. Journal of Hospitality \& Tourism Research, 35(1), 3-23. doi:10.1177/1096348010370857

Chen, Y.-S., \& Chang, C.-H. (2012). Enhance green purchase intentions The Roles of Green Perceived Value,Green Perceived Risk and Green Trust. Management Decision, 50(3), 502-520. doi:10.1108/00251741211216250

Corporation, S. (2011). Economic Census 2011. Department of Statistics Malaysia.

David, K., \& Kirk, D. (1995). Environmental management in hotels. International Journal of Contemporary Hospitality Management, 7(6), 3-8.

Gopal, K., \& Mohd Sulaiman, S. (2013). Circular on new definition of Small and Medium Enterprises (SMEs).

Graci, S. (2006). Accomodating gree: Examining barriers to sustainable tourism development. In TTRA Canada Conference Proceedings. (pp. 15-17). Montebello, Quebec.

Hillary, R. (2004). Environmental management systems and the smaller enterprise. Journal of Cleaner Production, 12(6), 561-569. doi:10.1016/j.jclepro.2003.08.006

Ikediashi, D. I., Ogunlana, S. O., Oladokun, M. G., \& Adewuyi, T. (2013). Assessing the level of commitment and barriers to sustainable facilities management practice: A case of Nigeria. International Journal of Sustainable Built Environment, 1, 167-176. doi:10.1016/j.jisbe.2013.06.002

Jaafar, M., Ing, T. K., \& Mohd Sukarno, S. Z. (2011). Problems of small and medium budget hotel operators. Special Issue of Tourism \& Hospitality, $12,73-79$.

Jamaludin, M., \& Yusof, Z. B. (2013). Best Practice of Green Island Resorts. Procedia - Social and Behavioral Sciences, 105, $20-29$. doi:10.1016/j.sbspro.2013.11.003

KamalulAriffin, N. S., Khalid, S. N. A., \& Wahid, N. A. (2013). The barriers to the adoption of environmental management practices in the hotel industry: A study of Malaysian hotels. Business Strategy Series, 14(4), 106-117. doi:10.1108/BSS-06-2012-0028

Kasim, A. (2009). Managerial attitudes towards environmental management among small and medium hotels in Kuala Lumpur. Journal of Sustainable Tourism, 17(6), 709-725. doi:10.1080/09669580902928468

Kirkland, L.-H., \& Thompson, D. (1999). Challenges in designing, implementing and operating an environmental management system. Business Strategy and the Environment, 8, 128-143.

McKeiver, C. (2005). Environmental Management Systems in Small and Medium Businesses. International Small Business Journal, 23(5), 513-537. doi:10.1177/0266242605055910

Menon, A., Menon, A., Chowdhury, J., \& Jankovich, J. (1999). Evolving Paradigm for environmental sensitivity in marketing programs: A synthesis of theory and practice. Journal of Marketing Theory and Practice, 7(2), 1-15.

Molina-Azorín, J. F., Claver-Cortés, E., Lopez-Gamero, M. D., Tarí, J. J., López-Gamero, M. D., \& Tarí, J. J. (2009). Green management and financial performance: a literature review. Management Decision, 47(7), 1080-1100. doi:10.1108/00251740910978313

Rahman, I., Reynolds, D., \& Svaren, S. (2012). How "green" are North American hotels ? An exploration of low-cost adoption practices. International Hospitality Management, 31, 720-727. doi:10.1016/j.jhm.2011.09.008

Ramirez, E. (2010). Three essays on green marketing strategy. Florida State University.

Thomas, R., Shaw, G., \& Page, S. J. (2011). Understanding small firms in tourism: A perspective on research trends and challenges. Tourism Management, 32(5), 963-976. doi:10.1016/j.tourman.2011.02.003

Tzschentke, N. a., Kirk, D., \& Lynch, P. a. (2008). Going green : Decisional factors in small hospitality operations. International Journal of Hospitality Management, 27(1), 126-133. doi:10.1016/j.jijhm.2007.07.010

Walker, B., Janice, R., Lynnaire, S., Calvin, W., \& Ute, G. (2008). Small and medium enterprises and the environment : barriers , drivers, innovation and best practice. A review of the literature March 2008. Swan Catchment Council.

Yacob, P., Aziz, N. S., Mohamad Makmor, M. F., \& Mohd zin, A. W. (2013). The policies and green practices of Malaysian SMEs. Global Business and Economics Research Journal, 2(2), 52-74. Retrieved from http://www.journal.globejournal.org/index.php/GBERJ/article/view/23

Yacob, P., \& Moorthy, M. K. (2012). Green Practices : Perception of Malaysian SME Owners / Managers. International Journal of Academic Research in Economics and Management Science, 1(3), 103-111.

Yusof, Z. B., \& Jamaludin, M. (2013). Green Approaches of Malaysian Green Hotels and Resorts. Procedia - Social and Behavioral Sciences, 85, $421-431$. doi:10.1016/j.sbspro.2013.08.371

Yusof, Z. B., \& Jamaludin, M. (2014). Barriers of Malaysian Green Hotels and Resorts. Procedia - Social and Behavioral Sciences, 00, 1-11. 